\title{
A FORMAÇÃO CONTINUADA DE PROFESSORES A PARTIR DE PESQUISAS ACADÊMICAS: TENDÊNCIAS E PERSPECTIVAS
}

\section{THE TEACHERS CONTINUING FORMATION FROM ACADEMIC RESEARCH: TENDENCIES AND PERSPECTIVES}

\author{
DEIMLING, Natalia Neves Macedo \\ natanema@gmail.com \\ Universidade Tecnológica Federal do Paraná \\ BORGES, Fabiana Vigo Azevedo \\ fabianavigo@hotmail.com \\ Iseb - Instituto Superior de Educação de Barretos \\ CORRÊA, André Garcia \\ andregcorrea@gmail.com \\ IFSP - Instituto Federal de Educação, Ciência e Tecnologia de São Paulo
}

\begin{abstract}
RESUMO Objetivamos neste artigo analisar as contribuições derivadas das teses e dissertações defendidas entre os anos de 2000 e 2010 no Programa de Pós-Graduação em Educação da UFSCar. Foi realizada uma pesquisa bibliográfica a partir da consulta aos trabalhos relacionados a essa temática. A análise dos trabalhos foi realizada à luz de estudos que discutem sobre a formação de professores. A partir dessa análise, observamos que tanto as pesquisas que analisam políticas ou programas de formação continuada quanto àquelas que têm por objetivo elaborar, desenvolver e avaliar programas de formação se preocupam em investigar as contribuições que os programas de formação continuada tem trazido para a prática profissional e para os processos de aprendizagem e desenvolvimento profissional de educadores.

Palavras-chave: Formação continuada de professores. Estado da arte. Pesquisa em Educação.

ABSTRACT In this article we analyze the contributions derived from theses and dissertations between 2000 and 2010 in the Post-Program degree in Education of the UFSCar. A literature search from the query related to this theme available. The analysis of the work was done in the light of studies that discuss the training of teachers and. From this analysis, we note that both studies analyze policies or programs of continuing formation as those that aim to design, develop and evaluate training programs bother to investigate the contributions of continuing education programs has brought to professional practice and to the processes of learning and professional development of educators, especially teachers of basic education.
\end{abstract}


Key-words: Teachers continuing formation. State of the art. Education research.

\section{CONSIDERAÇÕES INICIAIS}

Estudos sobre o "estado da arte" de produções acadêmicas objetivam apresentar um panorama geral sobre as principais tendências investigativas de pesquisa e seus resultados alcançados, visando colaborar, desta maneira, para o desenvolvimento de novos estudos na área. Tendo isso em vista, objetivamos com esse trabalho discutir e analisar como a temática Formação Continuada tem sido abordada em algumas teses e dissertações brasileiras defendidas e publicadas no Programa de Pós-Graduação em Educação (PPGE) da Universidade Federal de São Carlos (UFSCar), local em que os autores deste artigo realizaram suas pesquisas .

Mesmo considerando os limites de nosso trabalho, esperamos contribuir para uma melhor compreensão das tendências e dos desafios postos às pesquisas em Educação, especialmente no que se refere à temática "Formação Continuada". Com este, buscamos oferecer aos estudiosos da área uma referência sobre os principais problemas investigados e resultados já alcançados nessa linha de pesquisa, bem como uma base para o desenvolvimento de novos estudos e investigações.

Para a realização desse estudo, foram consultados dezesseis trabalhos desenvolvidos na linha de pesquisa "Formação de professores e outros agentes educacionais, novas tecnologias e ambientes de aprendizagem" defendidos entre os anos de 2000 e 2010 no PPGE da UFSCar. Tal estudo é resultado de um amplo trabalho realizado no âmbito da disciplina "Estudos em Formação de Professores", ofertada no primeiro semestre de 2011 neste mesmo Programa de Pós-Graduação, bem como de nosso interesse em aprofundar nossos conhecimentos sobre a temática, tendo em vista nossa atuação como professores e pesquisadores na área.

Em um primeiro momento, foi realizado por todos os estudantes dessa disciplina um levantamento do número de dissertações e teses defendidas nesse período por meio da consulta ao currículo lattes dos professores que compõem a linha de pesquisa mencionada, disponível na Plataforma Lattes do CNPq (Conselho Nacional de Desenvolvimento Científico e Tecnológico). A partir da leitura exploratória de todos os 
trabalhos, foram selecionados aqueles que tratavam diretamente do tema "Formação de Professores", totalizando 78 trabalhos. Em seguida, foi elaborado um quadro síntese de cada trabalho, a fim de categorizá-los a partir dos seguintes itens: título, ano de publicação, autor, orientador, área de concentração, questão de pesquisa, objetivo, principais conceitos e referenciais teórico-metodológicos utilizados, método e procedimentos metodológicos, participantes, instrumentos de coleta dos dados, instrumentos de análise dos dados, principais resultados e conclusões.

Após esse primeiro levantamento, os trabalhos foram reorganizados a partir de sua temática principal, segundo dados apresentados no Quadro 1:

Quadro 1: Número de trabalhos de acordo com a temática estudada

\begin{tabular}{|l|l|c|}
\hline \multicolumn{1}{|c|}{ Temas } & \multicolumn{1}{c|}{ Subtemas } & Número de trabalhos \\
\hline Formação inicial & & 11 \\
\hline Formação continuada & & 16 \\
\hline Professor iniciante & & 12 \\
\hline \multirow{2}{*}{ Práticas pedagógicas } & Saberes docentes & 13 \\
\cline { 2 - 3 } & Inclusão, diversidade e tecnologias & 12 \\
\cline { 2 - 3 } & Matemática/língua portuguesa & 14 \\
\hline
\end{tabular}

Fonte: autoria própria.

Neste artigo, analisamos os trabalhos relacionados à categoria "Formação Continuada", temática de maior recorrência nas pesquisas que tratam sobre Formação de Professores neste Programa de Pós-Graduação.

Para a análise das teses e dissertações relacionadas a essa temática, norteamonos por um roteiro que inclui informações sobre: 1) identificação dos trabalhos - título, autor, orientador, ano de publicação, natureza (mestrado ou doutorado) e veículo/suporte (digital ou impresso) -; 2) análise descritiva - tema abordado, problema de pesquisa, contexto investigado, referenciais teóricos e metodológicos, metodologia de pesquisa, participantes/fontes de dados, resultados e conclusões -; 3) análise crítica - principais tendências investigativas e perspectivas para o desenvolvimento de novas pesquisas na área.

A seguir, apresentamos uma análise dos trabalhos a partir do roteiro proposto, buscando apontar as principais tendências investigativas, suas implicações teóricas e práticas e suas contribuições para os estudos desenvolvidos na linha de pesquisa 
"Formação de professores", tendo como base alguns autores da área que discutem essa temática.

\section{O QUE DIZEM AS TESES E DISSERTAÇÕES: ALGUMAS DISCUSSÕES}

Foram analisados, ao todo, 16 trabalhos, sendo oito pesquisas de mestrado e oito pesquisas de doutorado. A maioria dos trabalhos (13) está disponível na forma impressa e online - na Biblioteca Digital de Teses e Dissertações da Biblioteca Comunitária da UFSCar -, enquanto apenas três encontram-se, exclusivamente, na forma impressa.

Abaixo, apresentamos uma tabela com o nome dos autores e orientadores das pesquisas, o título dos trabalhos, sua natureza e ano de publicação em ordem cronológica.

Quadro 2: Identificação das teses e dissertações selecionadas

\begin{tabular}{|l|l|c|c|}
\hline \multicolumn{1}{|c|}{ Autor } & \multicolumn{1}{|c|}{ Título } & Natureza & Ano \\
\hline $\begin{array}{l}\text { Heloísa Raimunda } \\
\text { Herneck }\end{array}$ & $\begin{array}{l}\text { Analisando contribuições de uma política educacional de } \\
\text { formação continuada para a aprendizagem da docência - } \\
\text { o caso do PROCAP }\end{array}$ & Mestrado & 2002 \\
\hline $\begin{array}{l}\text { Natal Lânia Roque } \\
\text { Fernandes }\end{array}$ & $\begin{array}{l}\text { Navegando no espaço de formação: o processo de } \\
\text { construção de conhecimento docente em informática na } \\
\text { educação }\end{array}$ & Mestrado & 2002 \\
\hline $\begin{array}{l}\text { Maria José Lenharo } \\
\text { Morgado }\end{array}$ & $\begin{array}{l}\text { Formação de Professores de Matemática para o Uso } \\
\text { Pedagógico de Planilhas Eletrônicas de Cálculo: Análise } \\
\text { de um Curso a Distância Via Internet }\end{array}$ & Doutorado & 2003 \\
\hline $\begin{array}{l}\text { Lilian Aparecida } \\
\text { Ferreira }\end{array}$ & $\begin{array}{l}\text { O professor de educação física no primeiro ano da } \\
\text { carreira: análise da aprendizagem profissional a partir da } \\
\text { promoção de um programa de iniciação a docência }\end{array}$ & Doutorado & 2005 \\
\hline $\begin{array}{l}\text { Lucélio Ferreira } \\
\text { Simião }\end{array}$ & $\begin{array}{l}\text { A informática e a formação continuada de professores: } \\
\text { analisando aprendizagens e processos }\end{array}$ & Doutorado & 2006 \\
\hline $\begin{array}{l}\text { Renata Portela } \\
\text { Rinaldi }\end{array}$ & $\begin{array}{l}\text { Informática na educação: um recurso para a } \\
\text { aprendizagem e desenvolvimento profissional de } \\
\text { professoras-mentoras ons }\end{array}$ & Mestrado & 2006 \\
\hline $\begin{array}{l}\text { Evandro Antônio } \\
\text { Bertoluci }\end{array}$ & $\begin{array}{l}\text { Formação continuada online de professores dos anos } \\
\text { iniciais: contribuiçães para a ampliação da base de } \\
\text { conhecimento para o ensino de Geometria }\end{array}$ & Doutorado & 2007 \\
\hline $\begin{array}{l}\text { Heloísa Raimunda } \\
\text { Herneck }\end{array}$ & $\begin{array}{l}\text { Formação continuada de professores: níveis de } \\
\text { compreensão de uma política pública }\end{array}$ & Doutorado & 2007 \\
\hline $\begin{array}{l}\text { Raquel Duarte de } \\
\text { Souza }\end{array}$ & $\begin{array}{l}\text { Era uma vez... Aprendizagens de professoras } \\
\text { escrevendo histórias infantis para ensinar matemática }\end{array}$ & Mestrado & 2007 \\
\hline $\begin{array}{l}\text { Patrícia Cristina } \\
\text { Silva Leme }\end{array}$ & $\begin{array}{l}\text { Formação e atuação de educadores ambientais: análise } \\
\text { de um processo educativo na universidade }\end{array}$ & Doutorado & 2008 \\
\hline Sydione Santos & $\begin{array}{l}\text { Processos formativos e reflexivos: contribuiçães para o } \\
\text { desenvolvimento profissional de professores }\end{array}$ & Doutorado & 2008 \\
\hline
\end{tabular}


DOl: http://dx.doi.org/10.7867/1809-0354.2016v11n1p65-91

\begin{tabular}{|l|l|c|c|}
\hline $\begin{array}{l}\text { Josiane Posati Dal- } \\
\text { Forno }\end{array}$ & $\begin{array}{l}\text { Formação de formadores e educação inclusiva: análise } \\
\text { de uma experiência via internet }\end{array}$ & Doutorado & 2009 \\
\hline $\begin{array}{l}\text { Maria Cristina } \\
\text { Pedrino }\end{array}$ & $\begin{array}{l}\text { Processos de Formação de Professoras Alfabetizadoras: } \\
\text { Construção de Saberes Docentes }\end{array}$ & Mestrado & 2009 \\
\hline Regina Helena Silva & $\begin{array}{l}\text { Formação Continuada de Professores em Serviço: Em } \\
\text { Busca de um Currículo em Ação Multicultural }\end{array}$ & Mestrado & 2009 \\
\hline $\begin{array}{l}\text { Renata Portela } \\
\text { Rinaldi }\end{array}$ & $\begin{array}{l}\text { Desenvolvimento profissional de formadores em } \\
\text { exercício: contribuições de um programa online }\end{array}$ & Doutorado & 2009 \\
\hline $\begin{array}{l}\text { Luci Fátima } \\
\text { Montezuma }\end{array}$ & $\begin{array}{l}\text { Saberes mobilizados por um grupo de professoras diante } \\
\text { do desafio de integrar a Literatura Infanto-juvenil e a } \\
\text { Matemática }\end{array}$ & Mestrado & 2010 \\
\hline
\end{tabular}

Fonte: autoria própria.

A partir da leitura e análise dos trabalhos, foi possível elaborar a relação dos principais temas abordados.

Todas as pesquisas apresentam como tema principal a Formação de Professores e discutem o conceito com base em autores como Marcelo Garcia (2002), Tardif (2002), Nóvoa (1995), Mizukami (2002), Schön (1995), Zeichner (1993), entre outros. A partir do referencial teórico, os pesquisadores consideram, de modo geral, a formação docente como um processo contínuo, sistemático, organizado e permanente de desenvolvimento pessoal e profissional que permite um movimento de construção e reconstrução de conhecimentos profissionais.

Alguns temas secundários também foram identificados nos trabalhos, os quais se relacionam a alguns dos principais conceitos abordados nos estudos sobre formação de professores. Por exemplo, as pesquisas de Herneck (2002), Ferreira (2005), Rinaldi (2006), Souza (2007) e Leme (2008) discutem o processo de aprendizagem profissional da docência, tendo como principais referenciais teóricos Marcelo Garcia (2002) e Mizukami (2002). Nesses trabalhos, o conceito de aprendizagem profissional docente é compreendido, essencialmente, como um processo contínuo, que se inicia antes do exercício profissional e se estende por toda vida, sendo marcada por um conjunto de processos de aprendizagem que envolve aquisição e construção de conhecimentos teóricos e práticos oriundos de diferentes fontes de experiências.

O conceito de desenvolvimento profissional docente - que envolve, também, a aprendizagem profissional da docência -, foi igualmente discutido nos trabalhos de Rinaldi (2006), Simião (2006), Santos (2008), Dal-Forno (2009) e Rinaldi (2009), tendo como base, principalmente, os estudos de Marcelo Garcia (2002), Nóvoa (1995), 
Zeichner (1993), entre outros. Esses trabalhos compreendem o desenvolvimento profissional dos professores, de forma geral, como um processo permanente, contínuo e inconcluso que envolve o crescimento pessoal, a formação profissional e o desenvolvimento da atividade profissional em processos de formação continuada. Trata-se, de um fenômeno que ocorre ao longo de toda a vida, integrando-se as práticas sociais do cotidiano no qual o professor encontra-se inserido.

As pesquisas de Simião (2006), Pedrino (2009), Montezuma (2010) abordaram, também, o tema "saberes docentes", tendo como base teórica, principalmente, os estudos de Marcelo Garcia (2002), Zeichner (1993) e Tardif (2002). Nessas pesquisas, o saber docente foi apontado como essencial ao processo de formação profissional. Esses saberes, provenientes de diferentes fontes, relacionam-se, especialmente, à prática pedagógica do professor. Considerar esses saberes significa desenvolver um trabalho colaborativo com os professores, considerando suas experiências e conhecimentos como essenciais para o seu desenvolvimento profissional.

Já o conceito de base de conhecimento desenvolvido por Shulman $(2005)^{1} \mathrm{e}$ amplamente estudado no Brasil por Mizukami (2004) foi um dos temas discutidos, principalmente, nos trabalhos de Bertoluci (2007) e Montezuma (2010). Neles, a base de conhecimento para a docência foi compreendida, essencialmente, como o conjunto de compreensões, conhecimentos, habilidades e disposições necessárias para o professor ensinar. Trata-se de um repertório de conhecimentos que advém de fontes diversas e cuja construção se dá por meio de diferentes processos de aprendizagem, que também dependem do contexto no qual o professor está inserido. De modo geral, essa base de conhecimento envolve: o conhecimento do conteúdo específico, o conhecimento pedagógico geral e o conhecimento pedagógico do conteúdo.

O professor reflexivo e sua prática também foram discutidos nos trabalhos de Bertoluci (2007) e Santos (2008), tendo como base teórica, principalmente, os estudos de Zeichner (1993), Schön (1995) e Marcelo Garcia (2002). Esses trabalhos apontam o professor reflexivo como àquele que compreende e analisa suas ações pedagógicas e

\footnotetext{
${ }^{1}$ Sua primeira discussão sobre o tema foi realizada no artigo intitulado "Knowledge and teaching: the foundations of the new reform", publicado na Harvard Educational Review, em 1987.
} 
atribui a elas um significado. Ao refletir sobre sua prática, o professor desenvolve ações coerentes e intencionais, visando à possível e necessária transformação da realidade ${ }^{2}$.

De modo geral, podemos observar que os temas secundários abordados nas pesquisas analisadas compreendem, essencialmente, a aprendizagem profissional da docência, o processo de construção de conhecimento e da base de conhecimento para a docência, o desenvolvimento profissional e a construção dos saberes docentes no processo de formação continuada em diferentes áreas: ensino de matemática (SOUZA, 2007, MORGADO, 2003, BERTOLUCI, 2007, MONTEZUMA, 2010), ensino da língua materna (PEDRINO, 2009), educação ambiental (LEME, 2008), currículo multicultural e sensibilização docente (SILVA, 2009), literatura infanto-juvenil (MONTEZUMA, 2010), informática (FERNANDES, 2002; RINALDI, 2006; SIMIÃO, 2006), políticas públicas de formação (HERNECK, 2002, 2007), educação física (FERREIRA, 2005), inclusão escolar (DAL-FORNO, 2009) e iniciação a docência (FERREIRA, 2005). Devido aos temas investigados, foi possível observar certa coerência no referencial teóricometodológico adotado pelos pesquisadores.

Outros conceitos também foram discutidos, porém com menor frequência, como, por exemplo, os conceitos de trajetórias profissionais (HERNECK, 2002), epistemologia da prática docente (FERNANDES, 2002), educação ambiental (LEME, 2008), reflexibilidade (SANTOS, 2008), mentoria (FERREIRA, 2005; RINALDI, 2006), educação inclusiva (DAL-FORNO, 2009) e sensibilização docente (SILVA, 2009).

A formação no local de trabalho foi o foco de apenas duas das pesquisas analisadas. Silva (2009), em seu estudo de mestrado, buscou analisar os aspectos relacionados à diferença, igualdade e desigualdade nas diferentes práticas sociais do ambiente escolar e sensibilizar os professores para estas questões, visando à construção de um currículo intermulticultural. Para tanto, participou dos Horários de Trabalho Pedagógico Coletivo (HTPC) em uma escola de periferia do município de São Carlos-SP. Montezuma (2010), em sua pesquisa de mestrado, também se utilizou da formação em serviço, buscando investigar quais saberes foram mobilizados,

\footnotetext{
${ }^{2}$ A partir da análise, foi possível observar que a maioria das pesquisas discutiu e utilizou todos esses conceitos como referencial teórico do estudo. Todavia, buscamos aqui apresentar o principal tema/conceito abordado por cada uma das pesquisas.
} 
construídos e/ou ressignificados por um grupo de professoras em um curso de extensão, desenvolvido pela própria pesquisadora, tentando integrar literatura infantojuvenil com a matemática. $O$ curso foi realizado em uma escola estadual do município de Araraquara-SP.

Quantos aos problemas norteadores das pesquisas analisadas, podemos observar que aqueles propostos pelos trabalhos que buscaram analisar cursos ou políticas de formação continuada diferem-se daqueles propostos pelos trabalhos que objetivaram elaborar, desenvolver e avaliar cursos, programas ou atividades formativas. O primeiro grupo buscou, essencialmente, analisar e compreender as contribuições de cursos de formação continuada para o desenvolvimento e aprendizagem profissional de professores. Já o segundo grupo de trabalhos objetivou, tendo em vista a natureza das pesquisas, elaborar, desenvolver e avaliar cursos ou programas de formação continuada para o desenvolvimento e aprendizagem profissional docente, bem como para a construção de saberes e da base de conhecimento para a docência.

No que se refere às situações investigadas temos - como já apontamos -, de um lado, a análise de cursos ou políticas de formação continuada de profissionais da educação tendo em vista os processos de construção de conhecimento, de desenvolvimento profissional e aprendizagem profissional e, de outro, a elaboração, desenvolvimento e avaliação de cursos ou programas de formação continuada nas modalidades presencial e a distância. $O$ número de pesquisas que objetivou caracterizar e analisar cursos, programas ou políticas de formação continuada (oito pesquisas) foi o mesmo número de estudos que optaram pelo desenvolvimento de programas ou atividades formativas (oito pesquisas).

A maioria dos trabalhos que objetivaram analisar políticas ou programas de formação continuada é de nível mestrado (cinco trabalhos). Apenas dois trabalhos (RINALDI, 2006; MONTEZUMA, 2010) de mestrado tiveram por objetivo desenvolver e avaliar um processo formativo com os participantes da pesquisa. De outro lado, a maioria das pesquisas que objetivaram elaborar, desenvolver e avaliar programas de formação continuada é de nível doutorado (seis pesquisas), sendo que apenas três teses (HERNECK, 2007; LEME, 2008; SANTOS, 2008) buscaram analisar políticas ou programas de formação continuada de professores. Esses dados podem ser 
justificados, em certa medida, pelo tempo disponível para a realização das pesquisas em nível de mestrado e doutorado.

De acordo com André (2007), no caso dos mestrandos, o tempo de formação é curto demais (dois anos ou dois anos e meio), o que pode em alguns casos, comprometer a formação desse pesquisador e a qualidade da produção científica. Podemos considerar que o curto espaço de tempo que esses pesquisadores dispõem para o desenvolvimento de suas pesquisas não permite, na maioria dos casos, um projeto de intervenção que, por sua natureza, demandaria maior tempo de trabalho.

Já no caso dos doutorandos, as condições concretas de pesquisa são um pouco diferentes. De acordo com a autora, no doutorado o tempo de titulação é maior (cerca de quatro anos) e o número de créditos a cumprir, em geral, é menor do que para os mestrandos. Além disso, esses pesquisadores, ao ingressarem no doutorado, já possuem alguma experiência de pesquisa, o que lhes dá, aparentemente, melhores condições para produzir bons trabalhos. Nesses casos, os projetos de intervenção são mais bem aceitos, uma vez que nesse nível o pesquisador dispõe de mais tempo para o desenvolvimento de seu trabalho.

Todavia, o desenvolvimento de pesquisas-intervenção no mestrado e de estudos de cunho mais teórico no doutorado é igualmente relevante e não pode ser desprezado. O caminho metodológico que a pesquisa irá percorrer dependerá, em certa medida, da coerência e da viabilidade do projeto de pesquisa proposto e das condições concretas de trabalho do pesquisador.

É interessante observar o aumento de pesquisas que buscam desenvolver programas de formação docente, tendo como base os saberes práticos, as experiências e as necessidades apresentadas pelos professores, oferecendo-lhes maior participação no desenvolvimento desses programas. Trata-se de estudos que não visam, apenas, a análise do produto, mas também a análise do processo de aprendizagem e de desenvolvimento profissional desses professores.

Por muito tempo, a formação continuada de professores no Brasil foi compreendida como momentos de "reciclagem", "atualização" e "aperfeiçoamento" da formação inicial e da prática docente. Esse entendimento considerava a formação como momentos formais ou como um sinônimo de eventos intitulados de "capacitação". Esse 


\title{
DOI: http://dx.dol.org/10.7867/1809-0354.2016v11n1p65-91
}

modelo é coerente com a lógica da racionalidade técnica, segundo a qual a atividade profissional consiste na aplicação da teoria na prática (MIZUKAMI et al, 2002).

Para Mizukami et. al. (2002), esse modelo de formação apóia-se na idéia de acúmulo de conhecimentos ditos teóricos para posterior aplicação na prática, segundo o qual a atividade profissional consiste na resolução de problemas instrumentais tornado rigorosa por intermédio da aplicação da teoria. No entanto, embora essa lógica constitua um discurso teórico eficiente, pode ser posta em ação apenas em situações idealizadas de prática pedagógica.

Ferreira (2006) argumenta que propostas curriculares construídas sem considerar as opiniões e experiências do professor em exercício tendem a fracassar. Nelas, o professor sente-se como um mero realizador de propostas desenvolvidas por outras pessoas - pessoas que, muitas vezes, não tiveram experiências com a formação inicial de estudantes da Educação Básica. Essa postura, de certo modo, sugere um desprestígio da profissão do professor.

Com o objetivo de superar esse modelo de formação como racionalidade técnica, surge a concepção de formação docente como um continuum, um processo que se inicia antes da formação inicial e se prolonga por toda a vida em contínuo desenvolvimento, não se encerrando em uma única proposta (REALI, et al, 1995).

Como aponta Marcelo Garcia (2002),

\begin{abstract}
Em outro tempo se formava para toda uma vida, hoje em dia passamos a vida toda nos formando. E a formação nos aparece como o dispositivo que usamos para adaptar a formação de base que adquirimos (ensino secundário, universitário, profissional, etc.) as nossas necessidades ou da empresa onde trabalhamos. (MARCELO GARCÍA, 2002, pág. 32) ${ }^{3}$.
\end{abstract}

Esse autor defende que a formação docente deve envolver constantes aprendizagens e, para que seja de qualidade e significativa, não pode ser desenvolvida a partir de cursos "pré-moldados".

\footnotetext{
${ }^{3}$ Versão original: En otro tiempo uno se formaba para toda una vida, hoy día nos pasamos la vida formándonos. Y la formación se nos aparece como el dispositivo que empleamos para adaptar la formación de base que hemos adquirido (educación secundaria, universitaria, profesional, etc.) a nuestras necesidades o las de la empresa en la que trabajemos
} 
A concepção de formação docente como um continuum tem como foco as necessidades e o desenvolvimento profissional do professor, entendido como um sujeito de conhecimento que reflete sobre sua própria prática. Neste modelo, são consideradas a história e as experiências pessoais e profissionais do professor, as quais influenciam e interferem diretamente em seu trabalho pedagógico. Trata-se, portanto, de um fenômeno que ocorre ao longo de toda a vida e que se desenvolve de modo integrado às práticas sociais e às cotidianas escolares de cada professor. Neste modelo, a compreensão da formação continuada como momento de reciclagem ou atualização da formação inicial torna-se inviável. Para Candau (1996), essa concepção de formação enquanto desenvolvimento profissional defende que todo processo de formação continuada deve ter como referência fundamental o saber docente, 0 reconhecimento e a valorização do professor.

Trata-se, pois, de uma formação que parte da realidade prática do professor. De acordo com Shulman (2005), o conhecimento potencialmente codificável, que pode ser adquirido a partir da sabedoria adquirida com a prática, é muito amplo. Desse modo, são importantes iniciativas de formação que também considerem a realidade prática do professor e suas necessidades de formação.

Em um processo de formação onde se consideram as necessidades formativas docentes, o papel do professor é central. A partir do momento em que analisa, questiona e reflete sua própria prática, o professor se torna um importante agente para a efetivação de intervenções, inovações e práticas alternativas para sua atuação pedagógica. Quando concebida como um trabalho reflexivo, a formação continuada possibilita a crítica sobre as práticas, sendo o professor o investigador de sua própria prática. Ao assumir esse papel, ele se torna autônomo, sensível e atento à complexidade do espaço em que está inserido.

É importante, pois, destacar a relevância de programas formativos que considerem as necessidades dos professores e que trabalhem questões cotidianas de seu contexto profissional, promovendo a reflexão dos mesmos sobre suas práticas e acompanhando de perto suas aprendizagens. Esse é o caso de algumas das pesquisas analisadas, como as de Ferreira (2005), Rinaldi (2006), Bertoluci (2007), Dal-Forno (2009), Rinaldi (2009) e Montezuma (2010), as quais buscaram, a partir de um 
processo de colaboração com os professores, promover suas aprendizagens a partir do desenvolvimento de programas de formação que consideraram as necessidades formativas, o contexto profissional, os saberes do professor e seu processo reflexivo.

Zeichner (2008), um dos referenciais teóricos utilizados pelas pesquisas mencionadas, realiza uma análise crítica sobre o conceito de reflexão como conceito estruturante na formação docente. Para esse autor, o movimento sobre a prática reflexiva envolve reconhecer um papel ativo dos professores na formulação dos propósitos e finalidades de seu trabalho. Além disso, esse movimento tem por objetivo mostrar que a produção de conhecimento sobre boas práticas educativas não é exclusividade da academia, reconhecendo os professores também como construtores de conhecimento. Da ótica do professor, isso significa que "o processo de compreensão e de melhoria de seu próprio ensino deve começar da reflexão sobre sua própria experiência e que o tipo de saber advindo unicamente da experiência de outras pessoas é insuficiente" (ZEICHNER, 2008. p. 539).

Nessa perspectiva, são importantes atividades formativas que considerem 0 professor como sujeito dotado de conhecimento, capaz de realizar um papel central em seu processo de desenvolvimento profissional. Para tanto, é necessário realizar um trabalho colaborativo entre formadores e professores.

Questões sobre as abordagens metodológicas de pesquisa e o desenvolvimento de trabalho colaborativo entre pesquisador e participantes de pesquisas são discutidas por André (2007). A autora aponta que os estudos qualitativos, que englobam um conjunto heterogêneo de métodos, técnicas e análises ganharam força a partir da década de 1980, juntamente com o contexto de produção, que passou de situações controladas de experimentação para o exame de situações "reais" do cotidiano da escola e da sala de aula. Segundo a autora, o pesquisador, que antes assumia o papel de um sujeito de "fora" da situação investigada, hoje tem assumido e valorizado o olhar "de dentro", realizando trabalhos em que analisa sua própria experiência ou que desenvolve sua pesquisa em colaboração com os participantes. Podemos observar essa opção metodológica nas pesquisas analisadas.

Todos os trabalhos foram realizados a partir da abordagem qualitativa de pesquisa, sendo sete deles (FERREIRA, 2005; RINALDI, 2006; SIMIÃO, 2006; 
PEDRINO, 2009; DAL-FORNO, 2009; RINALDI, 2009) com ênfase no modelo construtivo-colaborativo de pesquisa-intervenção, tendo como base Cole \& Knowles. Segundo os autores dessas pesquisas, este modelo implica um trabalho processual, considerando que todos os envolvidos têm algo a aprender um com o outro, promovendo uma parceria entre pesquisador e participante e proporcionando aprendizagens mútuas num processo multifacetado e não hierarquizado.

Outros enfoques metodológicos também foram utilizados. Dois trabalhos desenvolveram um estudo descritivo-analítico de natureza qualitativa (HERNECK, 2002; SANTOS, 2008), dois indicaram ter desenvolvido um estudo de caso qualitativo (LEME, 2008; SANTOS, 2008), um trabalho desenvolveu pesquisa narrativa com abordagem qualitativa (HERNECK, 2007) e um trabalho configurou-se como observação participante de abordagem qualitativa (MONTEZUMA, 2010), na qual o pesquisador, numa participação direta, se integra ao contexto investigado.

Quanto aos participantes/fontes de dados, destacaram-se os professores da educação básica (11 trabalhos). Desses trabalhos, oito focaram os professores dos anos iniciais do ensino fundamental. Num segundo plano encontram-se os formadores de professores (dois trabalhos), professoras-mentoras (um trabalho) e demais profissionais da educação - educadores ambientais (um trabalho) e profissionais envolvidos com secretarias regionais de educação (um trabalho). Como conseqüência e predominantemente -, os professores configuraram-se como a população a que se dirigiam as pesquisas. Esse foco nos professores como participantes das pesquisas demonstra o interesse e a preocupação do PPGE da UFSCar e de seus pesquisadores com os profissionais que lidam diretamente com a prática de ensino desenvolvida em sala de aula.

Para o desenvolvimento dos estudos foram discriminados diferentes instrumentos de coleta de dados, haja vista a abordagem metodológica adotada pelas pesquisas - qualitativa. Dentre eles, destacaram-se as entrevistas, as narrativas escritas (diários reflexivos, relatos escritos) e os questionários. No estudo de Herneck (2008), a narrativa escrita configurou-se tanto como instrumento de coleta quanto metodologia de pesquisa. 


\section{DOI: http://dx.dol.org/10.7867/1809-0354.2016v11n1p65-91}

Em algumas pesquisas a observação, a análise documental, os memoriais de reunião e de aula, os arquivos audiovisuais e as interações - relatos escritos pelos participantes - em Ambientes Virtuais de Aprendizagem (AVA) também foram utilizados como instrumentos de coleta de dados.

Vale destacar a presença de estudos que utilizaram a Educação a Distância $(\mathrm{EaD})$ via internet como meio para o desenvolvimento da pesquisa e da intervenção propostas, como é o caso das pesquisas de Morgado (2003), Rinaldi (2006), Bertoluci (2007), Dal-Forno (2009) e Rinaldi (2009). Esses estudos, baseados em autores como Marcelo García, Moran e Almeida, apontam a importância e os benefícios dessa modalidade de ensino para o desenvolvimento de programas de formação continuada que visem o trabalho colaborativo, a valorização e o desenvolvimento profissional de educadores.

Outro exemplo é o trabalho de doutorado realizado por Ferreira (2005), a qual utilizou o processo de mentoria ${ }^{4}$ para o desenvolvimento de sua intervenção com professores iniciantes de Educação Física. A mentoria também foi abordada na pesquisa de mestrado desenvolvida por Rinaldi (2006), a qual buscou desenvolver um processo formativo em informática com professoras experientes que seriam futuras mentoras do Programa de Mentoria do Portal dos Professores da UFSCar. Essa pesquisa teve por finalidade contribuir para a formação de mentores, responsáveis por atenuar o impacto das primeiras inserções profissionais dos professores iniciantes em sala de aula por meio da orientação aos mesmos na busca de soluções para possíveis problemas enfrentados na prática docente.

Segundo Gatti (2008), a EaD tem sido nos últimos anos o caminho mais escolhido para a educação continuada de professores pelas políticas públicas tanto em nível federal como estadual e municipal. Isso se justifica pela flexibilidade dos tempos formativos que essa modalidade de ensino oferece aos trabalhadores, permitindo a compatibilização com diversos tipos jornadas de trabalho.

\footnotetext{
${ }^{4}$ Programa de Mentoria do Portal dos Professores da UFSCar - experiência pioneira no Brasil, oferecida no formato online para professores em início de carreira. Entre outros aspectos, visa proporcionar apoio e assessoria didática a esses professores, favorecendo seu bem-estar pessoal e profissional e facilitando sua adaptação e integração crítica ao sistema de ensino, à realidade da escola e da comunidade e a seus pares. Disponível em: < http://www.portaldosprofessores.ufscar.br/>. Acesso em: 22/10/2011.
} 
Marcelo Garcia (2002) apresenta alguns benefícios da EaD para o processo formativo. Dentre eles, podemos destacar a interatividade, a qual permite que o profissional tenha um papel ativo em sua formação de acordo com seu ritmo e nível de trabalho; a atualização permanente dos conteúdos e das atividades no AVA, as quais podem ser organizadas e recuperadas a qualquer momento pelos próprios alunos; as atividades síncronas e assíncronas, que permitem a participação dos alunos em diferentes atividades ao mesmo tempo, independentemente do local em que se encontram, bem como o estudo individual de acordo com o tempo do aluno. Além desses elementos, o autor argumenta sobre a disponibilidade dos recursos presentes na formação a distância via internet, os quais não necessitam se concentrar em um único espaço ou instituição. As potencialidades da rede permitem que os alunos possam utilizar os recursos e materiais didáticos em diferentes servidores da internet, bem como recorrer a formadores que não se encontram, necessariamente, no mesmo espaço geográfico no qual o curso é oferecido. Além disso, o autor destaca a comunicação horizontal existente entre os alunos e os formadores, haja vista que a colaboração faz parte desse modelo de formação.

Os trabalhos analisados que se utilizaram da $\mathrm{EaD}$ para o desenvolvimento da pesquisa e/ou da intervenção indicaram resultados e conclusões que vão ao encontro dos benefícios apontados por Marcelo García (2002), apresentando as potencialidades dessa modalidade de ensino para a formação de profissionais da educação. Os principais resultados e conclusões apontam que a EaD pode favorecer, entre outros aspectos, a troca de experiências para a busca de solução de problemas, o trabalho processual em "via de mão dupla" - comunicação horizontal entre formadores e formandos - e o trabalho colaborativo no processo educativo. $O$ apoio individualizado, 0 acompanhamento contínuo e as interações virtuais foram apontados tanto pelos pesquisadores como pelos participantes da pesquisa como elementos positivos e fundamentais do processo formativo a distância via internet.

As pesquisas que tiveram por objetivo analisar políticas ou cursos de formação continuada de professores (FERNANDES, 2002; HERNECK, 2002, 2007; SOUZA, 2007; LEME, 2008; SANTOS, 2008; SILVA, 2009; PEDRINO, 2009) apontam como principais resultados a descontinuidade das políticas de formação docente e a 
desarticulação entre a formação inicial e continuada. A desvalorização do professor, a desconsideração de seu contexto de trabalho e a questão do pouco tempo para a aprendizagem dos docentes foram também discutidas e apontadas por esses estudos como questões que podem afetar negativamente o processo de formação docente. Os estudos que focaram uma área de conhecimento específica também indicaram 0 desconhecimento do professor dos anos iniciais da educação básica sobre os conteúdos específicos que trabalham em sala de aula.

Alguns pontos positivos também foram apontados nesses estudos sobre a formação continuada de professores. Ao analisarem um programa de formação específico, as pesquisas apontaram como resultados que tais cursos contribuíram, em certa medida, para o desenvolvimento profissional dos envolvidos, proporcionando-lhes aprendizagens que contribuíram para sua atuação profissional. Essas pesquisas indicam a importância da valorização das experiências docentes e do envolvimento dos professores para o desenvolvimento dos cursos de formação e defendem a necessidade de esses cursos darem "voz" ao professor, a fim de trazer à tona sua subjetividade e experiências pessoais e profissionais.

Esses estudos apontam ainda que os processos formativos possibilitam a relação entre a base de conhecimento que o professor constrói e a projeção de uma nova prática docente a partir de elementos teóricos e práticos que se cruzam durante 0 percurso. Esses cursos, desenvolvidos a partir do contexto de trabalho dos professores, podem proporcionar o desenvolvimento de atitudes investigativas por parte dos mesmos na problematização de situações reais de ensino e aprendizagem, desencadeando, assim, a reflexão sobre suas ações. Os trabalhos em grupo e colaborativo também foram apontados por esses estudos como necessários ao desenvolvimento de atividades formativas que visem o compartilhamento de saberes e experiências que podem ser ressignificadas com a prática.

Em alguns desses estudos os professores participantes da pesquisa indicaram a importância de sempre estarem em busca de novos conhecimentos que fundamentem sua prática, considerando que o sucesso de seus alunos depende, em grande parte, da qualidade de sua formação e de seu trabalho. 
O grupo de pesquisas que objetivou desenvolver e avaliar programas formativos (MORGADO, 2003; FERREIRA, 2005; RINALDI, 2006, 2009; SIMIÃO, 2006; BERTOLUCI, 2007; DAL-FORNO, 2009; MONTEZUMA, 2010) apresentou em seus resultados os pontos positivos e os limites decorrentes do programa de formação proposto. Em alguns desses estudos, os participantes da pesquisa indicaram dificuldade em se exporem aos colegas no grupo de trabalho, o que acabava por limitar, em algumas situações, suas interações e suas aprendizagens. Houve também desistência de alguns participantes, os quais apontaram também a sobrecarga de trabalho na escola como um dos fatores que os levaram a desistir do curso. No que se refere aos programas de formação para o uso da informática ou desenvolvidos a distância via internet, os pesquisadores relatam as dificuldades encontradas pelos participantes no uso do computador. Nos trabalhos que utilizaram os AVA, foi apontado que algumas ferramentas utilizadas nesses ambientes se mostraram em alguns momentos complexas aos participantes inexperientes no uso das novas tecnologias e estreantes em processos formativos a distância. Problemas técnicos como, por exemplo, o funcionamento de algumas ferramentas do ambiente, também foram uma das principais dificuldades enfrentadas no desenvolvimento da pesquisa e da intervenção.

Quanto aos pontos positivos, essas pesquisas apontaram a importância dos momentos de compartilhamento de experiências e conhecimentos entre os professores para a busca de solução de problemas relativos ao desenvolvimento das atividades realizadas durante o processo formativo e que se relacionavam com as situações reais de sala de aula vivenciadas por esses professores. Para esses pesquisadores, a produção de práticas inovadoras surge a partir da reflexão sobre experiências partilhadas.

Alguns resultados evidenciaram ainda as potencialidades do programa de formação desenvolvido para a ampliação da base de conhecimento dos participantes, da reflexão de suas práticas profissionais e das aprendizagens relacionadas à sua atuação profissional, defendendo a necessidade de que os programas de formação de professores tenham como eixo o contexto de trabalho do educador. Os pesquisadores ressaltam a necessidade de que as propostas delineadas para educadores considerem 
o âmbito da escola e tenham como pano de fundo a reflexão deles sobre sua prática, bem como sobre suas crenças e concepções que, entrelaçadas aos seus conhecimentos, podem produzir novas prática.

O processo formativo, desenvolvido em "via de mão dupla" por meio da colaboração entre pesquisadores e participantes das pesquisas também foi apontado como ponto positivo da formação desenvolvida com os professores. Esses estudos evidenciam a valorização do professor como sujeito de conhecimento e investigador de sua própria prática e ressaltam a importância do trabalho colaborativo para 0 desenvolvimento e aprendizagem profissional docente. Alguns desses estudos indicaram que o trabalho colaborativo desenvolvido com os professores ao longo das atividades propostas pelo programa de formação proporcionou, também, parcerias de trabalho entre os pares no ambiente escolar.

Nessas pesquisas, os resultados indicaram que os temas abordados nos programas formativos devem estar ligados às demandas observadas na prática dos professores, bem como às suas necessidades formativas. $O$ apoio individualizado e 0 acompanhamento contínuo ao longo do programa de formação foram apontados pelos pesquisadores e participantes como aspectos fundamentais na construção das aprendizagens.

De modo geral, podemos observar que tanto as pesquisas que analisam políticas ou programas de formação continuada quanto àquelas que têm por objetivo elaborar, desenvolver e avaliar programas de formação apresentam a mesma preocupação: investigar as contribuições que os programas de formação continuada, desenvolvidos pelo Estado ou pelas Universidades para ou com os profissionais da educação nas modalidades presencial ou a distância, tem trazido para a prática profissional e para os processos de aprendizagem e desenvolvimento profissional de educadores, especialmente aos professores da educação básica.

\section{CONSIDERAÇÕES FINAIS}

Buscaremos neste momento apresentar algumas considerações que se delinearam no decorrer da presente pesquisa e que visam ampliar as reflexões acerca das tendências apresentadas e de alguns dos desafios postos às pesquisas em 
educação que têm se proposto a investigar o processo de formação continuada de professores.

A partir da análise realizada, podemos observar o interesse e a preocupação do PPGE-UFSCar e de seus pesquisadores com a formação dos profissionais que lidam diretamente com o processo de ensino-aprendizagem desenvolvido em sala de aula. Esses estudos, ao focarem a formação continuada, em particular do professor da educação básica, contribuem de forma significativa para os seus processos de aprendizagem e desenvolvimento profissional ao considerá-lo não como um mero sujeito de pesquisa, mas também - e, principalmente - como protagonista de seu desenvolvimento profissional. Essas pesquisas, de uma maneira geral, defendem o papel central do professor em sua formação, dando-lhes "voz" no momento da elaboração, desenvolvimento e/ou análise de processos formativos.

Observamos, também, um número significativo de pesquisas que buscam solucionar, com os professores, os problemas práticos decorrentes de sua atuação profissional a partir de uma formação que visa à valorização, a problematização e a relação entre os saberes teóricos e as experiências pessoais e profissionais dos docentes. Essas pesquisas, de uma maneira geral, desenvolveram suas investigações e intervenções com um número reduzido de participantes e tomaram um contexto específico (uma escola, um curso, etc.), orientados, essencialmente, para a solução de problemas práticos da realidade docente.

Mesmo reconhecendo a relevância de pesquisas dessa natureza para a formação de professores, devemos ser cautelosos ao sobrevalorizar esse tipo de estudo em detrimento de pesquisas, por exemplo, de cunho mais teórico.

De acordo com André (2007, p. 124), tem surgido, nos últimos anos, uma "tendência de apoio incondicional aos estudos que envolvem algum tipo de intervenção, aliada a uma crítica veemente ao caráter distante e acadêmico dos estudos produzidos na Universidade". Para a autora, essa tendência demonstra uma supervalorização da prática e um certo desprezo pela teoria.

Gatti (2001), em um balanço que realizou sobre a pesquisa em educação no Brasil, discute sobre as principais tendências dos trabalhos desenvolvidos na área. $A$ autora ressalta o sentido pragmático e um imediatismo específico presentes nas 
pesquisas em educação, nos quais os problemas e as metodologias propostas são, em geral, tratados de uma maneira um tanto simplista. Ainda reconhecendo a importância da análise de situações particulares, a autora afirma que devem ser também investigados problemas de espectro mais amplo. Para Gatti (2001), a pesquisa não pode estar apenas a serviço de solucionar pequenos impasses cotidianos, uma vez que o tempo da investigação científica "não se coaduna com as necessidades de decisões mais rápidas". E finaliza: "a busca da pergunta adequada, da questão que não tem resposta evidente é que constitui o ponto de origem de uma investigação científica" (GATTI, 2001, p. 71).

Tendo isso em vista, é importante que os pesquisadores em educação, ao proporem um projeto de estudo, levem em conta o rigor e a qualidade que uma pesquisa científica exige. $O$ estudo não deve, apenas, responder a um problema imediato, tampouco a interesses particulares.

É importante salientar que não estamos, aqui, desconsiderando a necessária origem prática dos temas e problemas de pesquisa, uma vez que os problemas em educação são também de natureza prática e, por esse motivo, as pesquisas necessitam contribuir com análises de problemas práticos para a melhoria da ação educativa. Todavia, concordamos com Duarte Neto (2013) quando afirma que o mundo não se resume apenas às nossas impressões e crenças, tampouco às nossas vivências cotidianas. Para o autor, a experiência empírica não é suficiente para responder à complexidade do processo educativo, uma vez que, para ser compreendida, é necessário considerá-la nas relações que a estruturam, as quais transcendem o campo do imediato. Assim, embora reconhecendo a importância das questões que no imediato são carentes de análise e proposições, é preciso que a pesquisa em Educação considere, igualmente, os problemas sociais, políticos e culturais mais amplos. Caso contrário, ela se tornará uma atividade superficial e simplista que, ao buscar solucionar problemas imediatos, confirmará uma prática adaptativa e não transformadora da realidade investigada.

Outros aspectos também merecem destaque. A partir da análise dos estudos, pudemos observar um aumento de pesquisas que têm o pesquisador não mais como aquele que analisa o objeto "do lado de fora", mas como o sujeito de sua própria 
pesquisa, o qual busca desenvolver, numa relação de horizontalidade, um trabalho de parceria com os participantes de seu estudo. É o caso de algumas das já mencionadas pesquisas-intervenção, nas quais o pesquisador assume o papel de ator e pesquisador, buscando o equilíbrio entre a ação e a investigação. André (2007, p. 124) ressalta as dificuldades de realização de uma pesquisa dessa natureza, pois, em muitos casos, o risco do pesquisador é muito grande de "sucumbir ao fascínio da ação, deixando para segundo plano a busca do rigor que qualquer tipo de pesquisa requer".

Sobre esse aspecto, a autora discute as posições trazidas por Miranda (2000, apud ANDRÉ, 2007) ao focalizar o tema da articulação ensino e pesquisa no debate sobre a formação de professores centrando-se, especificamente, na literatura que discute o professor reflexivo/pesquisador. Segundo Miranda, essa literatura suscita questões relativas às relações entre o conhecimento teórico e o conhecimento prático, levando, muitas vezes, a uma enfática crítica sobre o elitismo acadêmico. Para a autora, a literatura sobre o professor reflexivo/pesquisador tem vários méritos, dentre eles a valorização do professor como sujeito autônomo, dotado de conhecimento e que, por meio da reflexão, pode melhorar sua prática e combater desigualdades e exclusões.

Como pudemos observar, os estudos aqui analisados buscam esse caminho da valorização do professor como sujeito de conhecimento e, ao dar-lhes um papel de protagonistas, permite a reflexão e a investigação sobre sua própria formação e atuação pedagógica. Vale ressaltar, nesse contexto, a formação oferecida por meio da $\mathrm{EaD}$, a qual tem se mostrado uma forte aliada na promoção de espaços de diálogo e colaboração entre pesquisadores e professores e entre os professores, considerados, também, pesquisadores. Tendo em vista a flexibilidade, a atemporalidade e o respeito ao tempo de aprendizagem e desenvolvimento de cada um, essa modalidade de ensino permite que os sujeitos sejam ativos no processo de elaboração do conhecimento coletivo.

Todavia, independentemente da proposta de investigação - análise ou intervenção - e da modalidade de formação - presencial ou a distância -, é importante que os pesquisadores sejam cuidadosos ao se pautar nesses conceitos para o desenvolvimento de suas pesquisas, a fim de que o termo "professor reflexivo" não se torne um mero slogan utilizado de forma acrítica, sem o devido aprofundamento teórico 
que essa perspectiva de estudo requer. Miranda (2000, apud ANDRÉ, 2007) apresenta essa preocupação, argumentando que a adoção acrítica do termo nas pesquisas sobre formação de professores pode causar sérios problemas, como, por exemplo, atribuir ao professor toda a responsabilidade sobre seu insucesso profissional. Além disso, ao insistir num processo de reflexão orientado para a resolução de problemas imediatos da prática, essa perspectiva pode, ao invés de transformar o problema, adaptar-se a eles. Para a autora, a negação da teoria como parte necessária do processo de autonomia pode, ao invés de elevar, reduzir as reais possibilidades de reflexão crítica do professor. Da mesma forma, considerando o conhecimento apenas útil quando imediatamente aplicável à prática, estar-se-ia afastando esse profissional de uma reflexão teórica que não seja especificamente orientada a um fim imediato. Por fim, Miranda argumenta que a pesquisa deve ter uma formação teórica sólida, preocupada não apenas com os aspectos imediatos da vida escolar, mas também com outras questões mais amplas da sociedade.

Zeichner (2008) também nos chama a atenção sobre alguns elementos que podem minar o potencial da "reflexão" para o desenvolvimento profissional docente. Segundo o autor, "mesmo quando a reflexão é utilizada como um veículo para o desenvolvimento real dos professores, ela é vista como um fim em si mesmo, desconectado de questões mais amplas sobre a educação" (ZEICHNER, 2008. p.545). Geralmente, assume-se que professores reflexivos são, necessariamente, melhores profissionais. Contudo, o autor nos chama a atenção sobre as conseqüências mais amplas das decisões tomadas pelos professores em sala de aula. Além da reflexão sobre o conteúdo e sobre o conhecimento didático do conteúdo, o autor argumenta que os professores necessitam refletir sobre as possíveis consequências políticas que suas escolhas podem ocasionar em nível social.

A guisa de conclusão, podemos destacar mais três aspectos observados na análise das teses e dissertações.

Foram realizados poucos estudos que tiveram como foco o local de trabalho do(s) participante(s) da pesquisa. Apenas os trabalhos de Silva (2009) e Montezuma (2010) objetivaram a análise e o desenvolvimento de um processo formativo no local específico de trabalho dos professores. Tendo isso em vista, consideramos importante 
a realização de pesquisas - teóricas ou de intervenção - que, além de considerar o contexto de atuação do educador, analisem ou intervenham sobre sua formação em seu ambiente próprio de trabalho. A escola configura-se, também - mas não por si só -, como um importante espaço formativo para docentes e demais profissionais da educação que nela atuam.

Outro aspecto observado diz respeito aos participantes selecionados para o desenvolvimento das pesquisas analisadas. Como pudemos observar, a maioria dos trabalhos optaram, de acordo com sua natureza, por desenvolver o estudo com professores da educação básica. Apenas duas pesquisas (DAL-FORNO, 2009; RINALDI, 2009) desenvolveram seu estudo com formadores de professores, por exemplo. A escassez de pesquisas que tenham como foco os demais profissionais da educação - ao menos no âmbito do PPGE-UFSCar - demonstra a necessidade de novos estudos nessa perspectiva.

O último aspecto a ser observado se refere à necessidade de estudos nessa linha de pesquisa que considerem a formação de educadores que atuam, por exemplo, na Educação de Jovens e Adultos (EJA), na Educação Especial ou no contexto da inclusão escolar em salas comuns do ensino regular, em diferentes etapas da educação básica. Apenas a pesquisa desenvolvida por Dal-Forno (2009) teve como foco o desenvolvimento profissional de formadores tendo em vista a política de educação inclusiva. Assim, consideramos, igualmente, necessária a realização de pesquisas que investiguem o processo formativo desses profissionais, seja em pesquisas teóricas ou de intervenção, seja nas modalidades presencial ou a distância.

Considerando a importância de estudos de revisão sistemática da produção acadêmica sobre um tema para a compreensão do movimento da área, de sua configuração, propensões teórico-metodológicas, tendências, recorrências e lacunas, pensamos ser necessários novos trabalhos nessa perspectiva, que discutam sobre este e outros temas de pesquisa, tendo em vista a ampliação dessas discussões e uma melhor compreensão das perspectivas e dos desafios postos às pesquisas em Educação, bem como a constituição de bases e de referenciais para o desenvolvimento de novos estudos na área. 


\section{NATALIA NEVES MACEDO DEIMLING}

Pedagoga formada pela Universidade Estadual Paulista "Júlio de Mesquita Filho" (UNESP - Araraquara), Mestre em Educação Especial pela Universidade Federal de São Carlos (UFSCar) e Doutora em Educação pela mesma Universidade. Docente da Universidade Tecnológica Federal do Paraná, campus Campo Mourão.

\section{FABIANA VIGO AZEVEDO BORGES}

Formada em Pedagogia pela Universidade Federal de São Carlos (UFSCar) e em Artes Visuais pela Universidade de Brasília (UNB). Mestre em Educação pela UFSCar e Doutoranda em Educação pela mesma Universidade. Docente e Coordenadora Pedagógica do Ensino Fundamental no município de Barretos/ SP. Docente no curso de Pedagogia do Instituto Superior de Educação de Barretos.

\section{ANDRÉ GARCIA CORRÊA}

Licenciado em Música pela Universidade Federal de São Carlos (UFSCar) e Mestre em Educação pela mesma Universidade. Docente do Instituto Federal de Educação, Ciência e Tecnologia de São Paulo (IFSP) Campus Barretos e supervisor de tutoria virtual do curso de Licenciatura em Educação Musical da UAB/UFSCar.

\section{REFERÊNCIAS}

ANDRÉ, M. Questões sobre os fins e sobre os métodos de pesquisa em Educação. Revista Eletrônica de Educação, v.1, n.1, p. 199-131, 2007. Disponível em: <http://www.reveduc.ufscar.br/index.php/reveduc/article/viewFile/6/6> Acesso em: 27 mar. 2011.

BERTOLUCI, E. A. Formação continuada online de professores dos anos iniciais: Contribuições para a ampliação da base de conhecimento para o ensino de Geometria. 2007. Tese (Doutorado). Universidade Federal de São Carlos, São Carlos.

CANDAU, V. M. F. A formação continuada de professores: tendências atuais. In: REALI, Aline de M. R.; MIZUKAMI, M. da G. N. (Orgs). Formação de professores: tendências atuais. São Carlos: EDUFSCar, 1996. p. 139-152.

CNPq. Conselho Nacional de Desenvolvimento Científico e Tecnológico. Plataforma Lattes do CNPq. Disponível em: <www.cnpq.br>. Acesso em: 14/05/2011.

DAL-FORNO, J. P. Formação de formadores e educação inclusiva: análise de uma experiência via internet. 2009. Tese (Doutorado). Universidade Federal de São Carlos, São Carlos.

DUARTE NETO, J. H. A epistemologia da prática: implicações para a formação de professores da educação básica. Jundiaí: Paco Editorial, 2013, 276 p. 
FERNANDES, N. L. R. Navegando no espaço de formação: o processo de construção de conhecimento docente em informática na educação. 2002. Dissertação (Mestrado). Universidade Federal de São Carlos, São Carlos.

FERREIRA, A. C. O trabalho colaborativo como ferramenta e contexto para o desenvolvimento profissional: compartilhando experiências. In: NACARATO, A. M.; PAIVA, M. A. V. (orgs.). A formação do professor que ensina matemática: perspectivas e pesquisas. Belo Horizonte: Autêntica, 2006. p. 149-166.

FERREIRA, Lílian Aparecida. O professor de educação física no primeiro ano da carreira: Análise da aprendizagem profissional a partir da promoção de um programa de iniciação a docência. 2005. Tese (Doutorado). Universidade Federal de São Carlos, São Carlos.

GATTI, B. A. Análise das Políticas Públicas para a Formação Continuada no Brasil. Revista Brasileira de Educação, v.13, n.37. p. 57 -70, 2008.

GATTI, B. A. Implicações e Perspectivas da Pesquisa Educacional no Brasil Contemporâneo. Cadernos de Pesquisa, n. 113, p. 65-80, 2001.

HERNECK, H. R. Analisando contribuições de uma política educacional de formação continuada para a aprendizagem da docência - o caso do PROCAP. 2002. Dissertação (Mestrado). Universidade Federal de São Carlos, São Carlos.

HERNECK, Heloísa Raimunda. Formação continuada de professores: níveis de compreensão de uma política pública. 2007. Tese (Doutorado). Universidade Federal de São Carlos, São Carlos.

LEME, Patrícia Cristina Silva. Formação e atuação de educadores ambientais: análise de um processo educativo na universidade. 2008. Tese (Doutorado). Universidade Federal de São Carlos, São Carlos.

MARCELO GARCIA, C. Los professores como trabajadores del conocimiento: Certidumbre y desafios para una formación alo largo de la vida. Educar, 30, p. 27-56, 2002.

MIZUKAMI, M. G. N. et al. Escola e aprendizagem da docência: processos de investigação e formação. São Carlos: EdUFSCar, 2002, 203 p.

MIZUKAMI, M. G. N. Aprendizagem da docência: algumas contribuições de L. S. Shulman. Revista de Educação, v. 29, n. 2, 2004.

MONTEZUMA, Lucia Fátima. Saberes mobilizados por um grupo de professoras diante do desafio de integrar a literatura infanto-juvenil e a matemática. 2010. Dissertação (Mestrado). Universidade Federal de São Carlos, São Carlos. 
MORGADO, M. J. L. Formação de professores de matemática para o uso pedagógico de planilhas eletrônicas de cálculo: Análise de um curso a distância via internet. 2003. Tese (Doutorado). Universidade Federal de São Carlos, São Carlos.

NÓVOA, A. (Org.) Profissão professor. Porto: Porto Editora, 1995, 192 p. (Coleção Ciências da Educação).

PEDRINO, M. C. Processos de formação de professoras alfabetizadoras: Construção de saberes docentes. 2009. Dissertação (Mestrado). Universidade Federal de São Carlos, São Carlos.

REALI, A. M. M. R.; et al. O Desenvolvimento de um Modelo "Construtivo-Colaborativo" de Formação Continuada Centrado na Escola: Relato de uma experiência. Cadernos Cedes. Campinas. n. 36, p. 65-76, 1995.

RINALDI, R. P. Desenvolvimento profissional de formadores em exercício: contribuições de um programa online. 2009. Tese (Doutorado). Universidade Federal de São Carlos, São Carlos.

RINALDI, R. P. Informática na educação: Um recurso para a aprendizagem e desenvolvimento profissional de professoras-mentoras. 2006. Dissertação (Mestrado). Universidade Federal de São Carlos, São Carlos.

SANTOS, S. Processos formativos e reflexivos: contribuições para o desenvolvimento pessoal de professores. 2008. Tese (Doutorado). Universidade Federal de São Carlos, São Carlos.

SCHÖN, D. A. Formar professores como profissionais reflexivos. In: NÓVOA, A. (Org.). Os professores e a sua formação. 1995, p. 77-92.

SHULMAN, L. S. Conocimiento y enseñanza: fundamentos de la nueva reforma. Revista de currículum y formación del profesorado, v. 9, n. 2, p. 1-30, 2005.

SILVA, Regina Helena. Formação continuada de professores em serviço: Em busca de um currículo em ação multicultural. 2009. Dissertação (Mestrado). Universidade Federal de São Carlos, São Carlos.

SIMIÃO, Lucélio Ferreira. A informática e a formação continuada de professores: Analisando aprendizagens e processos. 2006. Tese (Doutorado). Universidade Federal de São Carlos, São Carlos.

SOUZA, Raquel Duarte. Era uma vez... Aprendizagens de professoras escrevendo histórias infantis para ensinar matemática. 2007. Dissertação (Mestrado). Universidade Federal de São Carlos, São Carlos. 
TARDIF, M. Saberes docentes e formação profissional. Petrópolis, RJ: Vozes, 2002, $325 \mathrm{p}$.

ZEICHNER, K. M. A formação reflexiva de professores: ideias e práticas. Lisboa: Educa, 1993, $131 \mathrm{p}$.

ZEICHNER, K. M. Uma Análise Crítica sobre a "Reflexão" como Conceito Estruturante na Formação Docente. Educação e Sociedade, Campinas, v. 29, n. 103, p. 535-554, 2008. 